\title{
Childhood intestinal parasitic infection and sanitation predictors in rural Dembiya, northwest Ethiopia
}

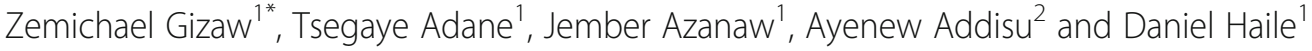

\begin{abstract}
Background: Intestinal parasites are a common problem in the world. The greater proportion of infections is associated with poor water, sanitation, and hygiene (WASH). This study was conducted to assess intestinal parasites, WASH condition, and their association in rural Dembiya, northwest Ethiopia.

Methods: A cross-sectional study was employed. Two hundred twenty-five children aged 6-59 months were included. Mothers were interviewed using a structured questionnaire, and the living environment was observed using checklists. Kato-Katz technique was used to determine the intensity of parasitic infections. Escherichia coli (E. coli) was used as a biological indicator for drinking water quality. Multivariable binary logistic regression analysis was conducted to identify WASH predictors of parasites on the basis of adjusted odds ratio (AOR) with 95\% confidence interval (Cl) and $p<0.05$.

Results: The prevalence of intestinal parasites was $25.8 \%(95 \% \mathrm{Cl}=20.3-32.0 \%)$. Ascaris lumbricoides (78\%), hookworm (12\%), Hymenolepis nana (7\%), Enterobius vermicularis (5\%), Schistosoma mansoni (3\%), Giardia lamblia (3\%), and Trichuris trichiuria (2\%) were identified infections. Intestinal parasites were associated with poor child hand washing practice [AOR $=3.86,95 \% \mathrm{Cl}=1.53,9.75]$, unprotected water sources $[\mathrm{AOR}=7.79,95 \% \mathrm{Cl}=3.30,18.40]$, access to water below $20 \mathrm{l} / \mathrm{c} / \mathrm{d}$ $[\mathrm{AOR}=3.05,95 \% \mathrm{Cl}=1.28,7.23]$, poor food safety[AOR $=4.33,95 \% \mathrm{Cl}=1.62,11.58]$, and poor sanitation $[\mathrm{AOR}=5.01,95 \%$ $\mathrm{Cl}=1.56,16.16]$.

Conclusion: A. lumbricoides, hookworm, H. nana, E. vermicularis, S. mansoni, G. lamblia, and T. trichiuria were identified. Child hand washing practice, service level of water supply, water sources, food safety, and sanitation were associated with intestinal parasites. WASH promotion is needed to prevent infections.
\end{abstract}

Keywords: Intestinal parasitic infections, WASH predictors, Children aged 6-59 months, Rural Dembiya

\section{Background}

Intestinal parasitic infections are major public health problems in the world, especially in developing countries causing under nutrition, anemia, intestinal obstruction, and mental and physical growth retardation [1]. Intestinal parasitic infections, mainly Ascariasis, Trichiuriasis, and hookworm, are common clinical disorders in man, with resultant impairments in physical, intellectual, and cognitive development [2]. About 3.5 billion people (the majority of these cases were children) in the world were infected with intestinal parasites caused by helminths and protozoa

\footnotetext{
* Correspondence: zemichael12@gmail.com

${ }^{1}$ Department of Environmental and Occupational Health and Safety, Institute of Public Health, College of Medicine and Health Sciences, University of Gondar, Gondar, Ethiopia

Full list of author information is available at the end of the article
}

during 2009 [3], and about 1.45 billion cases were due to soil-transmitted helminth (STH). Out of 1.45 billion infections due to STHs, 819.0 million were infected with A. lumbricoides, 464.6 million with $T$. trichiura, and 438.9 million with hookworm [4]. Of the 4.98 million years lived with disability (YLD) attributable to STH, $65 \%$ were attributable to hookworm, $22 \%$ to A. lumbricoides, and the remaining $13 \%$ to T. trichiura [4].

Intestinal parasitic infections are still major public health problems in sub-Saharan Africa. In sub-Saharan African countries, millions of people are infected with at least one intestinal parasitic infection. A global estimate shows that in the region, 118 million people (13.6\% of the population), 118 million people (13.6\% of the population), and 101 million people $(11.6 \%$ of the population) were infected by 
hookworm, A. lumbricoides, and T. trichiura, respectively, during 2010 [4] of which the majority were children [5].

In Ethiopia and other low-income countries including those in sub-Saharan Africa, the population suffers from a huge burden of potentially preventable diseases such as intestinal parasitic infections [6]. In Ethiopia and two other sub-Saharan African countries (Nigeria and the Democratic Republic of the Congo), STH infections account $8 \%$ of the global STH infections [4]. In the country, intestinal parasitic infections are prevalent among children. The global estimate during 2005 showed that 4882 school-aged children were infected with hookworm, 1956 with A. lumbricoides, 1983 with T. trichiura, and 7357 with other STH species [7].

Intestinal parasitic infections are caused by different factors, and the greater proportion of infections is associated with poor WASH conditions and most of the infections are fecal-oral [8-15]. WASH promotion is a planned and systematic activity to enable people to take action to improve WASH and to prevent or mitigate WASH-related diseases and to provide a practical way to facilitate community participation and accountability. It includes (i) access to facilities like community water supply system, waste management or sanitation facilities, and household-level technologies and materials; (ii) access to software services or community behavioral change services; and (iii) establish enabling environments like policy improvement, community organizations, sanitation financing, public-private partnership, and institutional strengthening [16]. In cognizant of the role of WASH promotion to prevent the transmission of intestinal parasitic infections, the University of Gondar in collaboration with Neglected Tropical Diseases Advocacy Learning Action (NALA) Foundation has been implementing WASH promotion project in rural Dembiya. This community-based cross-sectional study was conducted as a baseline survey to assess the prevalence and WASH predictors of intestinal parasitic infections among children aged 6-59 months.

\section{Methods}

\section{Study design and description of study settings}

A community-based cross-sectional study was conducted in May 2017 in rural Dembiya. Dembiya is one of the woredas in North Gondar Zone, the Amhara National Regional State, Ethiopia. Dembiya is bordered on the south by Lake Tana, on the southwest by Takusa, on the west by Chilga, on the north by Lay Armachiho, and on the east by Gondar Zuria [17]. The district finance and economic development report in June 2017 showed that Dembiya district had a total population of 326,686 , of whom 162,477 were men and 164,209 were women with 1:1 sex ratio. Under-five children accounted for $12.22 \%(39,927)$ of the total population [18]. Hygiene and sanitation-related communicable diseases were highly prevalent in the area. During June 2017, intestinal parasitic infections and diarrheal diseases were the top four and five prevalent diseases, which accounted 5161 (9.97\%) and 4981 (9.62\%), respectively. The population in the area had poor access to sanitation. During June 2017, clean water and latrine coverage in the district was 26.60 and 55\%, respectively [19].

\section{Sample size determination, sampling techniques, and sampling procedures}

The sample size was determined using single population proportion formula with the following assumptions: $p=$ 85.1\% (prevalence of intestinal parasitic infections among children aged 6-59 months in Shesha Kebkele, Wondo Genet, Southern Ethiopia during 2010) [20], 95\% confidence interval, and a $5 \%$ margin of error $(d)$.

$$
n=\frac{(z \alpha / 2)^{2} p(1-p)}{d^{2}}=\frac{(1.96)^{2} 0.851(1-0.851)}{0.05^{2}}=195
$$

By taking 15\% nonresponse rate, the final sample size became 225. Therefore, a total of 225 children aged 659 months were selected from five rural kebeles. The study subjects were selected by systematic random sampling technique. We spun an arrow at the center of the kebeles to identify the first household. The first household was selected randomly from 22 houses located in the direction of the arrow. The older one was selected in this study for households which had more than one child.

\section{Data collection procedures}

Data were collected using four different data collection methods. Children were provided a plastic stool container and asked to bring approximately $15 \mathrm{~g}$ of their own stool. For direct stool examination, a drop or drops of saline were placed on a slide. Approximately $0.05 \mathrm{~g}$ of stool specimen was placed using an applicator stick and mixed with a drop of saline and covered by cover slide. Finally, the specimen was examined under the microscope at low power $(\times 10$ objective) and high power ( $\times 40$ objective) magnifications for the identification of intestinal parasites [21]. For the Kato-Katz, a small amount (approximately $2 \mathrm{~g}$ ) of feces was placed on a piece of scrap paper. The stool was pressed on the top of the screen of the fecal specimen using the applicator stick. After the upper surface of the screen is scraped to sieve the fecal specimen, the template was placed on a clean microscopic slide and filled with the sieved fecal specimen. Then the template was removed carefully so that the entire fecal specimen remained on the slide. The remained fecal specimen was covered with glycerol-soaked cellophane strip and examined on the $\times 10$ objective microscope [21]. Stool specimen was analyzed immediately after collection. Examination of parasites was done by certified laboratory technicians. Water samples were taken from individual households at point of use 
using sterilized sampling bottles, and the samples were transported to the central laboratory within $4 \mathrm{~h}$ with cold chain. Moreover, the overall condition of water sampling was recorded on a checklist. The living environment and housing conditions were observed using checklists. Mothers were interviewed using a structured questionnaire. Field supervisors had also monitored the data collection process to assure data or sample quality.

\section{Measurement of study variables Prevalence of intestinal parasitic infection}

This is defined as the presence of one or more intestinal parasite species among children. The intensity of parasitic infections was also determined based on the number of parasitic eggs per gram (epg) of the stool sample. The intensity of Ascaris lumbricoides was classified into a light infection (1-4999 epg), moderate (5000-49,999 epg), and heavy (greater than 50,000 epg). The intensity of hookworm was classified into a light infection (1-1999 epg), moderate (2000-3999 epg), and heavy (greater than 4000 epg). The intensity of Schistosoma mansoni was also classified into a light infection (1-99 epg), moderate (100399 epg), and heavy (greater than 400 epg) [22-24].

\section{Hygiene of children and mother's hand washing practice}

The general cleanliness of the children was taken as "clean" if no any visible dirt on their clothes their figures and hand have no dirt, their hair is neat, their face is neat and wash their body regularly, and if they wear shoes. Mothers' or caregivers' hand washing practice was taken as "good" if they washed their hands with soap before meal, after defecation, after handling baby's diaper or feces, after meals, before feeding a child, before food preparation, and after handling rubbish or animals.

\section{Drinking water quality and access level}

Drinking water quality was taken as "good" if zero E. coli was found and "not good" if one or more E. coli were found in $100 \mathrm{ml}$ water sample [25]. Risk of drinking water was also classified into a different risk category based on colony-forming units (cfu) per $100 \mathrm{ml}$ of water. Risk category was taken as conformity $(0 \mathrm{cfu} / 100 \mathrm{ml})$, low risk $(1-10 \mathrm{cfu} / 100 \mathrm{ml})$, intermediate risk $(10-100 \mathrm{cfu} / 100 \mathrm{ml})$, high risk (100-1000 cfu/100 ml), and very high risk $(41,000 \mathrm{cfu} / 100 \mathrm{ml})$ [24, 26]. Drinking water sources were taken as "protected" if the community fetched water from protected springs or protected wells or public taps and "unprotected" if the water sources were rivers, unprotected springs, and unprotected wells. Drinking water supply service level was taken as "no access" and "basic access" if households had collected below 201 per capita per day $(\mathrm{l} / \mathrm{c} / \mathrm{d})$ and $20 \mathrm{l} / \mathrm{c} / \mathrm{d}$ and above water, respectively.

\section{Food safety practices}

Food safety practice was taken as "good" if a person who is responsible for food preparation did not prepare when he or she has diarrhea or other communicable diseases, if households washed fruits or vegetables before use, if food utensils were clean and stored in a clean area, if vectors or rodents were not seen in the food storage area, if households did not use leftover foods or reheat thoroughly before use, and if a person who is responsible for food preparation washed his/her hands before food preparation or if all family members washed their hands before eating, after visiting the toilet, and after of any manual works.

\section{Waste management practices}

Households' sanitation performance was taken as "adequate" if all the family members usually use a sanitary latrine, if functional handwashing facility was available around the latrine, if the living environment is free from rubbish and human and animal excreta, and if households disposed wastes hygienically.

\section{Data management and statistical analysis}

Data were entered using EPI-INFO version 3.5.3 statistical package and export into Statistical Package for Social Sciences (SPSS) version 20 for further analysis. For most variables, data were presented by frequencies and percentages. Univariable binary logistic regression analysis was used to choose sanitation variables for the multivariable binary logistic regression analysis, and variables which had $p$ value less than 0.2 by the univariable analysis were then analyzed by multivariable binary logistic regression for controlling the possible effect of confounders like the age of children, maternal education, and paternal education. Finally, variables which had significant association were identified on the basis of AOR with $95 \% \mathrm{CI}$ and $p<0.05$.

\section{Results}

Socio-demographic information of children and mothers In this study, a total of 225 children participated with 100\% response rate. The response rate was high because we collected and analyzed stool by moving from village to village with relevant treatment of infected children. Out of 225 children, 119 (52.9\%) were females. One hundred sixty-six (73.8\%) of the children were aged between 24 and 59 months. The median age of children was 42 months, and the interquartile range was 24-48 months. One hundred thirty-four (59.6\%) mothers aged 30 years and below. The fast majority, 180 (80.0\%), of the mothers and nearly two thirds, 139 (65.0\%), of the fathers did not attend formal education (Table 1).

\section{Prevalence of intestinal parasitic infections}

From a total of 225 children investigated, 58 of the children were infected with one or more intestinal parasitic 
Table 1 Socio-demographic information of households with children aged 6-59 months in rural Dembiya, northwest Ethiopia, May 2017

\begin{tabular}{lll}
\hline Variables & Frequency & Percent \\
\hline Sex of children & 106 & 47.1 \\
Male & 119 & 52.9 \\
$\quad$ Female & & \\
Age of children & 59 & 26.2 \\
$6-24$ & 166 & 73.8 \\
$>24$ & & \\
Maternal education & 180 & 80.0 \\
No formal education & 45 & 20.0 \\
Have formal education & & \\
Paternal education ( $n=214)$ & 139 & 65.0 \\
$\quad$ No formal education & 75 & 35.0 \\
Have formal education &
\end{tabular}

infections. The prevalence of intestinal parasitic infections among children aged 6-59 months in rural Dembiya was therefore found to be $25.8 \%$ ( $95 \% \mathrm{CI}=20.3-$ $32.0 \%)$. The commonest intestinal parasitic infection identified among children was Ascaris lumbricoides, which accounted 45 (77.6\%) (Fig. 1).

Besides prevalence, the intensity of infection was estimated from the number of eggs per gram (epg) of stool. Accordingly, the intensity of Ascaris lumbricoides infection was light (1-4999 epg). Similarly, the intensity of all other intestinal parasitic infections was light (see the classification of intensity of infections in the "Methods" section). The load of the egg of Ascaris lumbricoide was ranged from 24 to $5160 \mathrm{epg}$ of stool. Twenty-four to 336 eggs of Ascaris lumbricoide per gram of stool were found among 29 (64.3\%) of infected children. Nine (19.8\%) of the infected children had 360 to 961 eggs of Ascaris lumbricoide per gram of stool, and the rest, seven (15.4\%) had 1056 to $5160 \mathrm{epg}$ of stool. The egg load of hookworm among the infected children was from 24 to $792 \mathrm{epg}$ of stool. Five of hookworm-infected children had 24 to 48 epg of stool, and the rest, two had 120 and $792 \mathrm{epg}$ of stool. Two of the children infected by Hymenolepis nana had 72 epg, and the rest, two had 120 epg of stool. All of the three infected children by Enterobius vermicularis had $241 \mathrm{epg}$ of stool, and 48 eggs of Schistosoma mansoni per gram of stool was found among the two infected children.

\section{Hygiene of children}

Almost all 222 (98.7\%) of the children were unhygienic. Dirt was clearly seen on their fingers, face, hair, body, and clothes. Two thirds, 152 (67.6\%), of the households reported that they washed their child's face with clean water every morning. One hundred fifty-eight $(70.2 \%)$ of the households reported that their child washed its body once in 3 days. Nearly three fourth, 166 (73.8\%), of the children did not keep their fingernail short. One hundred sixty (71.1\%) of the children were barefooted at the time of the survey. Below half, 102 (45.3\%), of the households said that they frequently washed the hands of their children after playing, defecation, and before eating. Only a quarter, $55(24.4 \%)$, of mothers or caregivers washed their hands properly in different pick times (Table 2).

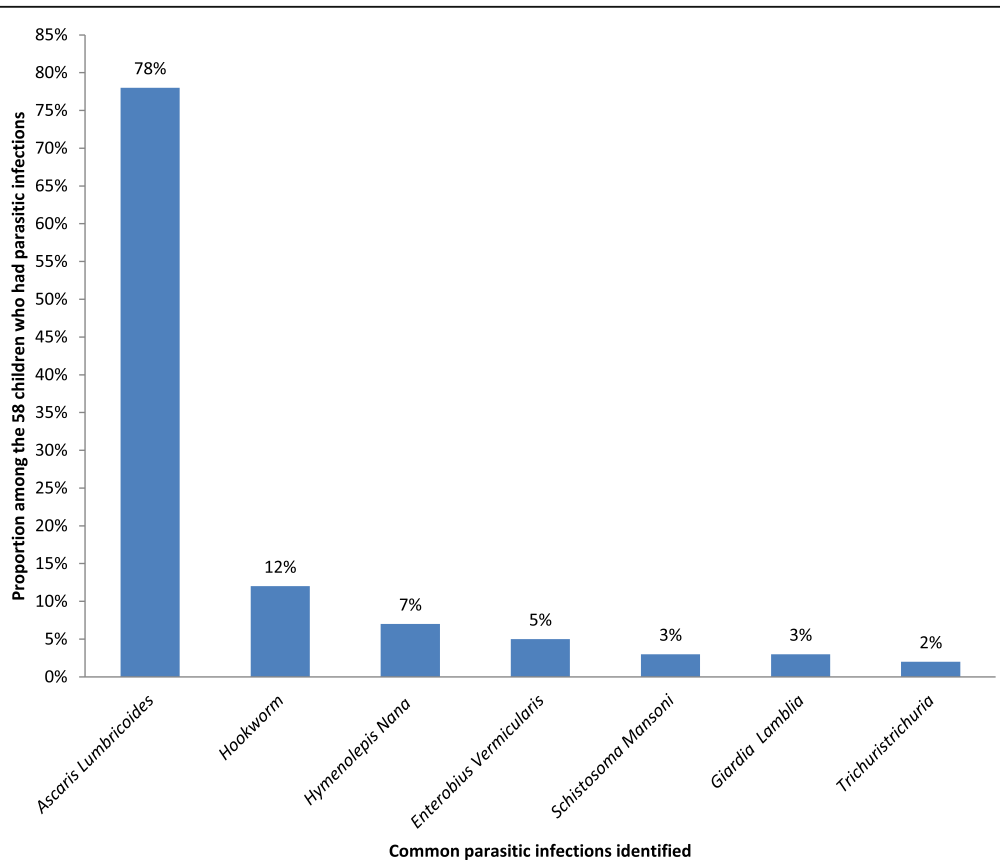

Fig. 1 Common intestinal parasitic infections identified among children aged 6-59 months in rural Dembiya, northwest Ethiopia, May 2017 
Table 2 Personal hygiene of children aged 6-59 months in rural Dembiya, northwest Ethiopia, May 2017

\begin{tabular}{|c|c|c|}
\hline Hygiene variables & Frequency & Percent \\
\hline \multicolumn{3}{|l|}{ General cleanliness of children } \\
\hline Clean & 3 & 1.3 \\
\hline Not clean & 222 & 98.7 \\
\hline \multicolumn{3}{|c|}{ Children wash their face with clean water in every morning } \\
\hline Yes & 152 & 67.6 \\
\hline No & 73 & 32.4 \\
\hline \multicolumn{3}{|c|}{ Children wash their body with clean water and soap } \\
\hline Once in 3 days & 158 & 70.2 \\
\hline Once a week & 67 & 29.8 \\
\hline \multicolumn{3}{|l|}{ Children's fingernails kept short } \\
\hline Yes & 59 & 26.2 \\
\hline No & 166 & 73.8 \\
\hline \multicolumn{3}{|l|}{ Children wear shoes } \\
\hline Yes & 65 & 28.9 \\
\hline No & 160 & 71.1 \\
\hline \multicolumn{3}{|c|}{$\begin{array}{l}\text { Children frequently wash their hands after playing, defecation, and } \\
\text { before eating }\end{array}$} \\
\hline Yes & 102 & 45.3 \\
\hline No & 123 & 54.7 \\
\hline \multicolumn{3}{|c|}{ Mothers' or caregivers' hand washing habits } \\
\hline Before meal & 223 & 99.1 \\
\hline After latrine use & 154 & 68.4 \\
\hline After handling baby's diaper/feces & 138 & 61.3 \\
\hline After meal & 209 & 92.9 \\
\hline Before feeding a child & 154 & 68.4 \\
\hline Before food preparation & 201 & 89.3 \\
\hline After handling rubbish/ animals & 112 & 49.8 \\
\hline \multicolumn{3}{|c|}{ Mothers' or caregivers hand washing practice } \\
\hline Good & 55 & 24.4 \\
\hline Not good & 170 & 75.6 \\
\hline
\end{tabular}

\section{Access to drinking water}

The majority of households, 190 (84.4\%), fetched drinking water from multiple sources. The commonest water sources were protected wells (Fig. 2). The water sources for $166(73.8 \%)$ households were protected. However, the bacteriological analysis of drinking water showed that $158(70.2 \%)$ of the households used water which was not good for consumption, and the water quality of nearly half, 107 (47.6\%), of the households was at high-risk level. The great majority, 205 (91.1\%), of the households reported that they had access to drinking water throughout the year, and 114 (50.7\%) households collected water below $20 \mathrm{l} / \mathrm{c} / \mathrm{d}$. The water storage containers in $199(88.4 \%)$ and 147 (65.3\%) households were not clean and not properly covered, respectively, at the time of the survey. Home-base water treatment was not commonly practiced in rural Dembiya. Seventeen (7.6\%) households treated drinking water at home. One household treated drinking water by solar disinfection. Thirteen households used water guard to treat water at home. Three households boiled drinking water before use (Table 3).

\section{Food safety practices}

The food safety practices of 107 (47.6\%) households were poor. One hundred forty $(62.2 \%)$ mothers or caregivers prepared food while they had diarrhea or other communicable diseases. Thirty-one (13.8\%) households did not wash fruits and vegetables before preparing for consumption. The majority, 203 (90.2\%), of the households did not keep food utensils clean, and food utensils were placed on the floor among 85 (37.8\%) households. Very few, 3 (1.3\%), households used properly maintained shelves to store food items, and vectors or rodents were observed around food storage areas in 113 (50.2\%) households. The overwhelming majority, 204 (90.7\%), of the households used leftover foods without reheating. Almost all, 221 (98.2\%), households prepared foods in dirty areas (Table 4).

\section{Waste management practices}

One hundred twenty-eight (56.9\%) of households had access to inadequate sanitation. All the family members did not utilize latrine among 153 (68\%) households, and human excreta was observed on the living compound of 101 (44.9\%) households. The majority, 201(89.3\%), and almost all, 216 (96.0\%), households disposed solid and liquid wastes on open field, respectively. Two hundred twelve (94.2\%) households did not clean their living compound at a regular basis (Table 5).

\section{WASH predictors of intestinal parasitic infections}

Table 6 shows WASH predictors associated with intestinal parasitic infections among children aged 659 months. Intestinal parasitic infections were statistically associated with child hand washing practice, drinking water sources, service level of drinking water supply, food safety practices, and households' sanitation performance. Socio-demographic confounders like the age of children, maternal education, and paternal education could not pass the model assumptions.

Children who did not wash their hands after playing/ defecation and before eating had higher odds to have intestinal parasitic infections. The prevalence of intestinal parasitic infections was 3.86 times more likely to be higher among children who did not wash their hands after playing/defecation and before eating $[\mathrm{AOR}=3.86$, $95 \% \mathrm{CI}=1.53,9.75]$. The probability of childhood intestinal parasitic infections was 7.79 times more likely to be 


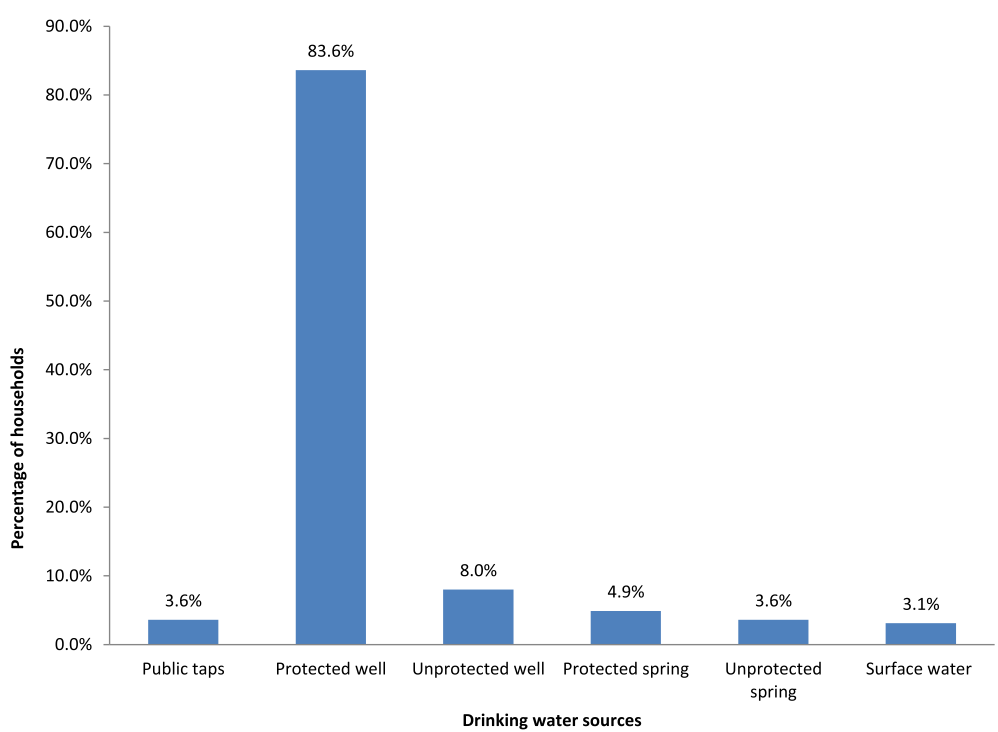

Fig. 2 Common drinking water sources for rural households in Dembiya, northwest Ethiopia, May 2017

higher if the households collected drinking water from unprotected sources $[\mathrm{AOR}=7.79,95 \% \mathrm{CI}=3.30,18.40]$. Intestinal parasitic infections among children were significantly associated with the service level of drinking water supply. Childhood parasitic infections were higher among households who collected water below $20 \mathrm{l} / \mathrm{c} / \mathrm{d}$ [AOR $=3.05$, 95\% $\mathrm{CI}=1.28,7.23]$. This study revealed that intestinal parasitic infections among children were statistically associated with households' food safety practices. Childhood intestinal parasitic infections were 4.33 times more likely to be higher among households whose food safety practice was poor [AOR $=4.33,95 \% \mathrm{CI}=1.62,11.58]$. Children who live in poor sanitation condition had higher odds to have intestinal parasitic infections compared with their counterparts $[\mathrm{AOR}=5.01,95 \% \mathrm{CI}=1.56,16.16]$.

\section{Discussion}

The prevalence of intestinal parasitic infections reported by this community-based cross-sectional study was $25.8 \%$ (95\% CI $=20.3-32.0 \%$ ). This may be due to the fact that the area is characterized by poor hygiene and sanitation conditions. As depicted by this study and reported by the District Health Office, the personal hygiene of children was poor, a greater proportion of caregivers practiced poor hand washing, most of the households accessed poor drinking water, and a significant proportion of households had poor food safety practice and sanitation conditions. Moreover, nearly half of the households had no health and WASH information and that could not practice infection prevention strategies at a regular basis. The prevalence reported by this study was lower than the findings of other similar community-based studies conducted in different parts of
Ethiopia, such as Wondo Genet (85.1\%) [20] and Hawassa Zuria District (51.3\%) [27]. The finding of this study was similar with the findings of other studies in Ethiopia like in Wonji Shoa Sugar Estate (24.3\%) [1] and Butajira town (23.3\%) [28]. Ascaris lumbricoides (78\%), hookworm (12\%), and Hymenolepis nana (7\%) were the most common parasitic infections identified in the present study. Even though the prevalence is not the same, other community-based studies also identified these intestinal parasitic infections as common infections $[1,20]$.

This study revealed that intestinal parasitic infection was higher among children who did not usually wash their hands after playing or defecation and before eating. Other similar studies reported about poor hand washing practice of children and risks of intestinal parasitic infections [29-32]. This can be due to the fact that children catch germs when they touch contaminated objects or surfaces or soil which increases the risk of hand contamination with diseases causing pathogens. Hand washing is the single most effective way to prevent the spread of infections [29, 33-35].

This community-based cross-sectional survey depicted that childhood parasitic infection was statistically associated with unprotected drinking water sources which is congruent with the findings of other studies [36-41]. This can be justified that unprotected sources are prone to contamination with different wastes and pathogenic organisms like cysts of protozoon species and eggs of worms which commonly transmitted to human by ingesting of contaminated water [42-45].

The service level of drinking water supply was significantly associated with intestinal parasitic infections. 
Table 3 Quality and access to drinking water in rural Dembiya, northwest Ethiopia, May 2017

\begin{tabular}{|c|c|c|}
\hline Variables & Frequency & Percent \\
\hline \multicolumn{3}{|l|}{ Drinking water quality } \\
\hline Good & 67 & 29.8 \\
\hline Not good & 158 & 70.2 \\
\hline \multicolumn{3}{|c|}{ Risk level of drinking water quality } \\
\hline Conformity & 67 & 29.8 \\
\hline Low risk & 12 & 5.3 \\
\hline Intermediate risk & 39 & 17.3 \\
\hline High risk & 107 & 47.6 \\
\hline \multicolumn{3}{|c|}{ Drinking water sources } \\
\hline Protected & 166 & 73.8 \\
\hline Unprotected & 59 & 26.2 \\
\hline \multicolumn{3}{|c|}{ More than one water source } \\
\hline Yes & 190 & 84.4 \\
\hline No & 35 & 15.6 \\
\hline \multicolumn{3}{|c|}{ The water source discharges water at any time } \\
\hline Yes & 205 & 91.1 \\
\hline No & 20 & 8.9 \\
\hline \multicolumn{3}{|c|}{ Service level of water supply } \\
\hline Basic access & 111 & 49.3 \\
\hline No access & 114 & 50.7 \\
\hline \multicolumn{3}{|c|}{ Cleanliness of drinking water storage containers } \\
\hline Clean & 26 & 11.6 \\
\hline Not clean & 199 & 88.4 \\
\hline \multicolumn{3}{|c|}{$\begin{array}{l}\text { Water storage containers were properly covered at the time of the } \\
\text { survey }\end{array}$} \\
\hline Yes & 78 & 34.7 \\
\hline No & 147 & 65.3 \\
\hline \multicolumn{3}{|c|}{ Treat water at household level } \\
\hline Yes & 17 & 7.6 \\
\hline No & 208 & 92.4 \\
\hline
\end{tabular}

Childhood parasitic infections were common among households who had no access to water $20 \mathrm{l} / \mathrm{c} / \mathrm{d}$ and above. This finding is in line with other similar studies $[46,47]$. This might be because of the shortage of water to keep personal hygiene. Most of the parasitic infections are fecal-oral $[39,48]$, meaning cysts of protozoon species and eggs of worms reach to our mouth via contaminated hand. Fecal-oral transmission of diseases is very common among communities characterized by poor hygiene due to the shortage of water [49].

Poor food safety practice was identified as a statistically significant variable with childhood intestinal parasitic infections. This finding is supported by the findings of other studies $[37,50]$. The best explanation for this could be that poorly prepared and handled food contains
Table 4 Food safety practices of rural households in Dembiya, northwest Ethiopia, May 2017

\begin{tabular}{lll}
\hline Variables & Frequency & Percent \\
\hline Food safety practices & & \\
Good & 118 & 52.4 \\
Poor & 107 & 47.6
\end{tabular}

Prepare food while you have diarrhea/or vomiting or other communicable diseases

$\begin{array}{lll}\text { Yes } & 140 & 62.2 \\ \text { No } & 85 & 37.8\end{array}$

Wash fruits or vegetables before preparing for consumption

$\begin{array}{lll}\text { Yes } & 194 & 86.2\end{array}$

$\begin{array}{lll}\text { No } & 31 & 13.8\end{array}$

Cleanliness of food utensils

$\begin{array}{lll}\text { Clean } & 22 & 9.8\end{array}$

Not clean $\quad 203 \quad 90.2$

Where food utensils are stored

$\begin{array}{lll}\text { On the floor } & 85 & 37.8\end{array}$

$\begin{array}{lll}\text { In shelves } & 140 & 62.2\end{array}$

How prepared foods stored

Stored at well-designed shelves $\quad 3 \quad 1.3$

$\begin{array}{lll}\text { Store separate from raw foods } & 183 & 81.3\end{array}$

$\begin{array}{lll}\text { Properly covered } & 33 & 14.7\end{array}$

The store is clean, illuminated, and ventilated $6 \quad 2.7$

Vectors or rodents are seen in food storage area

$\begin{array}{lll}\text { Yes } & 113 & 50.2\end{array}$

$\begin{array}{lll}\text { No } & 112 & 49.8\end{array}$

Reheat leftover foods to use

$\begin{array}{lll}\text { Yes } & 21 & 9.3\end{array}$

$\begin{array}{lll}\text { No } & 204 & 90.7\end{array}$

Cleanliness of food preparation area

$\begin{array}{lll}\text { Clean } & 4 & 1.8\end{array}$

$\begin{array}{lll}\text { Not clean } & 221 & 98.2\end{array}$

a number of disease-causing pathogenic microorganisms, and these pathogens can enter to our digestive system by ingestion of contaminated food [46, 51-54].

This study showed that intestinal parasitic infections were associated with poor sanitation condition. Poor sanitation (indiscriminate disposal of human excreta, liquid waste, and solid waste) results in disease-causing pathogens, especially infective eggs and larvae of helminths would litter the environment. As these diseases are transmitted by the fecal-oral route or by direct penetration of the skin, the risk of infection will increase with such environmental contamination [9, 13, 16, 51, 52]. Moreover, among human excreta, feces are the most dangerous to health. One gram of fresh feces from an infected person can contain around $10^{6}$ viral pathogens, 
Table 5 Waste management practices of rural households in Dembiya, northwest Ethiopia, May 2017

\begin{tabular}{lll}
\hline Variables & Frequency & Number \\
\hline Households sanitation performance & 97 & 43.1 \\
Adequate & 128 & 56.9 \\
Not adequate & 72 & \\
All members of the household use latrine & 153 & 32.0 \\
$\quad$ Yes & & 68.0 \\
No & 101 & \\
The living compound is free from human excreta & 124 & 44.9 \\
Yes & & 55.1 \\
No & 201 & 89.3 \\
Management of solid waste & 24 & 10.7 \\
Open dump & & \\
Sanitary disposal (burning and burying) & 9 & 96.0 \\
Liquid waste management & 216 & \\
Discard into soak pit or absorption pit & & 9.8 \\
Discharge to open field & 13 & \\
Do you clean the compound regularly & 212 & \\
Yes & &
\end{tabular}

$10^{6}-10^{8}$ bacterial pathogens, $10^{4}$ protozoan cysts, and $10-10^{4}$ helminth eggs [55].

\section{Limitation of the study}

Though it is highly recommended, this research did not use floatation techniques/McMaster technique to detect hookworm because the McMaster chamber was not available in the country. We used standardized wet mount preparation and Kato-Katz techniques. We examined each specimen within $1 \mathrm{~h}$ of sampling time to effectively detect hookworm. Different research articles suggest that intestinal parasitic infection is higher among older children in the 659 months age range because older children are more active and contact with fecally contaminated soil while playing, which could predispose them to intestinal parasitic infections [23, 56]. For this reason, the older one was selected in this study for households which had more than one child. Therefore, that fact should be considered when interpreting the estimate of "the prevalence of intestinal parasitic infections among children aged 6-59 months in rural Dembiya".

Table 6 Factors affecting intestinal parasitic infection among children aged 6-59 months in rural Dembiya, northwest Ethiopia, May 2017

\begin{tabular}{|c|c|c|c|c|}
\hline \multirow[t]{2}{*}{ Variables } & \multicolumn{2}{|c|}{ Parasitic infections } & \multirow[t]{2}{*}{ COR with $95 \% \mathrm{Cl}$} & \multirow[t]{2}{*}{ AOR with $95 \% \mathrm{Cl}$} \\
\hline & Yes & No & & \\
\hline \multicolumn{5}{|c|}{ Children wash their hands after playing/defecation and before eating } \\
\hline Yes & 10 & 92 & 1 & \\
\hline No & 48 & 75 & $5.89(2.79,12.42)$ & $3.86(1.53,9.75)^{* *}$ \\
\hline \multicolumn{5}{|c|}{ Mothers' or caregivers' hand washing practice } \\
\hline Good & 10 & 45 & 1 & \\
\hline Not good & 48 & 122 & $1.77(0.83,3.79)$ & $2.32(0.81,6.68)$ \\
\hline \multicolumn{5}{|c|}{ Drinking water sources } \\
\hline Protected & 22 & 144 & 1 & \\
\hline Unprotected & 36 & 23 & $10.25(5.14,20.41)$ & $7.79(3.30,18.40)^{* * *}$ \\
\hline \multicolumn{5}{|c|}{ Service level of water supply } \\
\hline Basic access & 24 & 87 & 1 & \\
\hline No access & 34 & 80 & $1.54(0.84,2.82)$ & $3.05(1.28,7.23)^{*}$ \\
\hline \multicolumn{5}{|c|}{ Drinking water quality } \\
\hline Good & 13 & 54 & 1 & \\
\hline Not good & 45 & 113 & $1.65(0.82,3.32)$ & $1.61(0.64,4.02)$ \\
\hline \multicolumn{5}{|c|}{ Food safety practices } \\
\hline Good & 9 & 109 & 1 & \\
\hline Poor & 49 & 58 & $10.23(4.70,22.30)$ & $4.33(1.62,11.58)^{* *}$ \\
\hline \multicolumn{5}{|c|}{ Households sanitation performance } \\
\hline Adequate & 5 & 92 & 1 & \\
\hline Not adequate & 53 & 75 & $13.00(4.95,34.17)$ & $5.01(1.56,16.16)^{*}$ \\
\hline
\end{tabular}

Hosmer and Lemeshow test $=0.095$

* Statistically significant at $p<0.05$

** Statistically significant at $p<0.01$

***Statistically significant at $p<0.001$ 


\section{Conclusion}

The prevalence of intestinal parasitic infections among children aged 6-59 months in rural Dembiya was high. Ascaris lumbricoides, hookworm, Hymenolepis nana, Enterobius vermicularis, Schistosoma mansoni, Giardia lamblia, and Trichuris trichuria were identified. Child hand washing practice, drinking water sources, service level of drinking water supply, food safety practices, and households' sanitation performance were the WASH predictors statistically associated with intestinal parasitic infections. Deworming should be done for infected children. Moreover, WASH promotion should be implemented to prevent the occurrence and transmission of intestinal parasitic infections in the long run. The community should have access to facilities like community water supply system, waste management or sanitation facilities, and household-level technologies and materials. Moreover, the community should have access to software services or community behavioral change services to promote WASH.

\section{Abbreviations}

AOR: Adjusted odds ratio; cfu: Colony-forming units; Cl: Confidence interval; COR: Crude odds ratio; E. coli: Escherichia coli; epg: Eggs per gram; JDC: Jewish Distribution Committee; NALA: Neglected Tropical Diseases Advocacy Learning Action; SPSS: Statistical Package for Social Sciences; STH: Soil-transmitted helminth; WASH: Water, sanitation, and hygiene; YLD: Years lived with disability

\section{Acknowledgements \\ The authors are pleased to acknowledge the data collectors, field supervisors, and study participants for their unreserved contributions to the success of this study. The authors are also pleased to acknowledge NALA Foundation for funding the project. NALA Foundation is an Israel-based nongovernmental organization developed into a thriving organization, working in many commu- nities both on the ground and giving technical assistance to local authorities. NALA works together with local, national, and international partners.}

\section{Funding}

The study was funded by NALA Foundation.

\section{Availability of data and materials}

Data will be made available upon request to the primary author.

\section{Authors' contributions}

All the authors actively participated during the conception of the research issue, development of a research proposal, data collection, analysis and interpretation, and writing various parts of the research report. ZG designed the protocol, analyzed the data, supervised the overall research process, and prepared the manuscript. DH and AA developed the data collection tools. TA and JA entered the data into Epi Info epidemiological software. All the authors read and approved the final manuscript.

\section{Ethics approval and consent to participate}

Ethical clearance was obtained from the Institutional Review Board of the University of Gondar, and an official letter was submitted to the district administrators. There were no risks due to participation in this research project, and the collected data were used only for this research purpose. Verbal informed consent was obtained from the mothers. The information collected from each household kept with complete confidentiality. Appropriate anthelmintic drugs or dewormings were given to children infected with intestinal parasitic infections together with brief health messages for the mothers or caregivers.

\section{Competing interests}

The authors declare that they have no competing interests.

\section{Publisher's Note}

Springer Nature remains neutral with regard to jurisdictional claims in published maps and institutional affiliations.

\section{Author details}

${ }^{1}$ Department of Environmental and Occupational Health and Safety, Institute of Public Health, College of Medicine and Health Sciences, University of Gondar, Gondar, Ethiopia. ${ }^{2}$ Department of Parasitology, School of Biomedical Science, College of Medicine and Health Sciences, University of Gondar, Gondar, Ethiopia.

Received: 10 February 2018 Accepted: 29 May 2018

Published online: 22 June 2018

\section{References}

1. Degarege A, Erko B. Prevalence of intestinal parasitic infections among children under five years of age with emphasis on Schistosoma mansoni in Wonji Shoa Sugar Estate, Ethiopia. PLoS One. 2014;9(10):e109793.

2. Bethony J, Brooker S, Albonico M, Geiger SM, Loukas A, Diemert D, Hotez PJ. Soil-transmitted helminth infections: ascariasis, trichuriasis, and hookworm. Lancet. 2006;367(9521):1521-32.

3. Brooker S, Kabatereine NB, Smith JL, Mupfasoni D, Mwanje MT, Ndayishimiye O, Lwambo NJ, Mbotha D, Karanja P, Mwandawiro C. An updated atlas of human helminth infections: the example of East Africa. Int J Health Geogr. 2009;8(1):42

4. Pullan RL, Smith JL, Jasrasaria R, Brooker SJ. Global numbers of infection and disease burden of soil transmitted helminth infections in 2010. Parasit Vectors. 2014;7:37.

5. Hall A, Hewitt G, Tuffrey V, De Silva N. A review and meta-analysis of the impact of intestinal worms on child growth and nutrition. Matern Child Nutr. 2008:4(s1):118-236.

6. World Health Organization report, 2017. Available at http://www.who.int/ countries/eth/coop_strategy/en/index1.html. Accessed 02 Dec 2017.

7. Brooker S, Clements AC, Bundy DA. Global epidemiology, ecology and control of soil-transmitted helminth infections. Adv Parasitol. 2006;62:221-61.

8. Bdir S, Adwan G. Prevalence of intestinal parasitic infections in Jenin Governorate, Palestine: a 10-year retrospective study. Asian Pac J Trop Med. 2010;3(9):745-7.

9. Oswald WE, Stewart AE, Kramer MR, Endeshaw T, Zerihun M, Melak B, Sata E, Gessese D, Teferi T, Tadesse Z. Association of community sanitation usage with soil-transmitted helminth infections among school-aged children in Amhara Region, Ethiopia. Parasit Vectors. 2017;10(1):91.

10. Al-Mohammed HI, Amin TT, Aboulmagd E, Hablus HR, Zaza BO. Prevalence of intestinal parasitic infections and its relationship with sociodemographics and hygienic habits among male primary schoolchildren in Al-Ahsa, Saudi Arabia. Asian Pac J Trop Med. 2010;3(11):906-12.

11. AE-S FA, Salama RA, Taha NS. Predictors of the intestinal parasitic infection among pre-school children in rural lower, Egypt. Egypt J Community Med. 2009:27:17-34.

12. Strunz EC, Addiss DG, Stocks ME, Ogden S, Utzinger J, Freeman MC. Water, sanitation, hygiene, and soil-transmitted helminth infection: a systematic review and meta-analysis. PLoS Med. 2014;11(3):e1001620.

13. Ziegelbauer K, Speich B, Mäusezahl D, Bos R, Keiser J, Utzinger J. Effect of sanitation on soil-transmitted helminth infection: systematic review and meta-analysis. PLoS Med. 2012;9(1):e1001162.

14. Schüle SA, Clowes P, Kroidl I, Kowuor DO, Nsojo A, Mangu C, Riess H, Geldmacher C, Laubender RP, Mhina S. Ascaris lumbricoides infection and its relation to environmental factors in the Mbeya region of Tanzania, a cross-sectional, population-based study. PLoS One. 2014;9(3):e92032.

15. Riess H, Clowes P, Kroidl I, Kowuor DO, Nsojo A, Mangu C, Schüle SA, Mansmann U, Geldmacher C, Mhina S. Hookworm infection and environmental factors in Mbeya region, Tanzania: a cross-sectional, population-based study. PLoS Negl Trop Dis. 2013;7(9):e2408.

16. Asaolu S, Ofoezie I. The role of health education and sanitation in the control of helminth infections. Acta Trop. 2003;86(2):283-94.

17. Gonder Awraja, Amhara Regional State, Ethiopia — list of all places. Available at http://www.placebeam.com/?r=poi\&l=13.16667\&g=37\&type=all\&title= Gonder\%20Awraja\%2C\%20Amhara\%20Regional\%20State\%2C\%20Ethiopia. Accessed 02 Dec 2017

18. Dembiya district finance and economic development office annual report 2017, by Zewudu Fetene and others, Koladiba: officer of finance and economic development, Amhara Region, Ethiopia, 2017. 
19. Dembiya district health office annual report 2017, by Tsigereda Kefale and others, Koladiba: officer of district health office, Amhara Region, Ethiopia, 2017.

20. Nyantekyi LA, Legesse M, Belay M, Tadesse K, Manaye K, Macias C, et al. Intestinal parasitic infections among under-five children and maternal awareness about the infections in Shesha Kekele, Wondo Genet, Southern Ethiopia. Ethiop J Health Dev. 2010;24(3):185-90.

21. World Health Organization. Training manual on diagnosis of intestinal parasites based on the WHO bench aids for the diagnosis of intestinal parasites, district laboratory practice in tropical countries. WHO/CTD/SIP/98.2 CD-Rom 2004. Available at http://usaf.phsource.us/PH/PDF/HELM/ trainingmanual_sip98-2.pdf. Accessed 01 Nov 2017.

22. Helminthiases WS-t. Eliminating soil-transmitted helminthiases as a public health problem in children: progress report 2001-2010 and strategic plan 2011-2020. France: World Health Organization; 2012. p. 19-29.

23. Sun C. Prevalence and associated risk factors of Intestinal Helminths infections among pre-school children (1 to 5 years old) in IDPs settlements of Khartoum state, Sudan. J Global Health. 2015. Available at http://www. ghjournal.org/prevalence-and-associated-risk-factors-of-intestinal-helminthsinfections-among-pre-school-children-1-to-5-years-old-in-idps-settlementsof-khartoum-state-sudan/. Accessed 09 May 2018.

24. Sanchez AL, Gabrie JA, Usuanlele M-T, Rueda MM, Canales M, Gyorkos TW. Soiltransmitted helminth infections and nutritional status in school-age children from rural communities in Honduras. PLoS Negl Trop Dis. 2013;7(8):e2378.

25. Edberg SC, Rice EW, Karlin RJ, Allen MJ. Escherichia coli: the best biological drinking water indicator for public health protection. Symp Ser Soc Appl Microbiol. 2000(29):106s-16s.

26. Gwimbi P. The microbial quality of drinking water in Manonyane community: Maseru District (Lesotho). Afr Health Sci. 2011;11(3):474-80.

27. Kabeta A, Assefa S, Hailu D, Berhanu G. Intestinal parasitic infections and nutritional status of pre-school children in Hawassa Zuria District, South Ethiopia. Afr J Microbiol Res. 2017;11(31):1243-51.

28. Shumbej T, Belay T, Mekonnen Z, Tefera T, Zemene E. Soil-transmitted helminths and associated factors among pre-school children in Butajira town, south-central Ethiopia: a community-based cross-sectional study. PLoS One. 2015;10(8):e0136342.

29. Haas JP. Handwashing and nail clipping reduce risk of intestinal parasite infection in school-age children. Evid Based Nurs. 2016;19(2):49.

30. Mahmud MA, Spigt M, Bezabih AM, Pavon IL, Dinant G-J, Velasco RB. Efficacy of handwashing with soap and nail clipping on intestinal parasitic infections in school-aged children: a factorial cluster randomized controlled trial. PLoS Med. 2015;12(6):e1001837.

31. Freeman M, Chard A, Nikolay B, Garn J, Okoyo C, Kihara J, Njenga S, Pullan R, Brooker S, Mwandawiro C. Associations between school-and household-level water, sanitation and hygiene conditions and soil-transmitted helminth infection among Kenyan school children. Parasit Vectors. 2015;8(1):412.

32. Gelaw A, Anagaw B, Nigussie B, Silesh B, Yirga A, Alem M, Endris M, Gelaw B. Prevalence of intestinal parasitic infections and risk factors among schoolchildren at the University of Gondar Community School, northwest Ethiopia: a cross-sectional study. BMC Public Health. 2013;13(1):304.

33. Mathur P. Hand hygiene: back to the basics of infection control. Indian J Med Res. 2011;134(5):611.

34. Aiello AE, Coulborn RM, Perez V, Larson EL. Effect of hand hygiene on infectious disease risk in the community setting: a meta-analysis. Am $J$ Public Health. 2008;98(8):1372-81.

35. Bloomfield SF, Aiello AE, Cookson B, O'boyle C, Larson EL. The effectiveness of hand hygiene procedures in reducing the risks of infections in home and community settings including handwashing and alcohol-based hand sanitizers. Am J Infect Control. 2007;35(10):S27-64.

36. Michael E, Abah A, Marcus P. Intestinal parasitic infection among primary school children in Port Harcourt City Local Government Area of Nigeria: a review for school-based intervention. Adv Tech Clin Microbiol. 2017;1(4):19.

37. Asemahagn MA. Parasitic infection and associated factors among the primary school children in Motta town, Western Amhara, Ethiopia. American Journal of Public Health Research. 2014;2(6):248-54.

38. Maru DS. Prevalence of intestinal parasitic infections and associated risk factors among school children in Adigrat town, northern Ethiopia. Int J Emerg Trends in Sci Technol. 2015;4(1):4943-8.

39. Matthys B, Bobieva M, Karimova G, Mengliboeva Z, Jean-Richard V, Hoimnazarova M, Kurbonova M, Lohourignon LK, Utzinger J, Wyss K. Prevalence and risk factors of helminths and intestinal protozoa infections among children from primary schools in western Tajikistan. Parasit Vectors. 2011;4(1):195.

40. Steinmann P, Usubalieva J, Imanalieva C, Minbaeva G, Stefiuk K, Jeandron A, Utzinger J. Rapid appraisal of human intestinal helminth infections among schoolchildren in Osh oblast, Kyrgyzstan. Acta Trop. 2010;116(3):178-84.

41. Ouattara M, N'Guéssan NA, Yapi A, N'Goran EK. Prevalence and spatial distribution of Entamoeba histolytica/dispar and Giardia lamblia among schoolchildren in Agboville area (Côte d'Ivoire). PLoS Negl Trop Dis. 2010; 4(1):e574.

42. Shields KF, Bain RE, Cronk R, Wright JA, Bartram J. Association of supply type with fecal contamination of source water and household stored drinking water in developing countries: a bivariate meta-analysis. Environ Health Perspect. 2015;123(12):1222.

43. Shaheed A, Orgill J, Montgomery MA, Jeuland MA, Brown J. Why? Improved? Water sources are not always safe. Bull World Health Organ. 2014;92(4):283-9.

44. Omar MS, Mahfouz AA, Moneim MA. The relationship of water sources and other determinants to prevalence of intestinal protozoal infections in a rural community of Saudi Arabia. J Community Health. 1995;20(5):433-40.

45. Amenu D, Menkir S, Gobena T: Microbiological quality of drinking water sources and water handling practices among rural communities of Dire Dawa Administrative Council. 2014.

46. Nyarango RM, Aloo PA, Kabiru EW, Nyanchongi BO. The risk of pathogenic intestinal parasite infections in Kisii municipality, Kenya. BMC public health. 2008;8(1):237.

47. Echazú A, Bonanno D, Juarez M, Cajal SP, Heredia V, Caropresi S, Cimino RO, Caro N, Vargas PA, Paredes G. Effect of poor access to water and sanitation as risk factors for soil-transmitted helminth infection: selectiveness by the infective route. PLoS Negl Trop Dis. 2015;9(9):e0004111.

48. Ali SA, Hill DR. Giardia intestinalis. Curr Opin Infect Dis. 2003;16(5):453-60.

49. Idowu O, Rowland S. Oral fecal parasites and personal hygiene of food handlers in Abeokuta, Nigeria. African health sciences. 2006;6(3):160-4.

50. Abate A, Kibret B, Bekalu E, Abera S, Teklu T, Yalew A, Endris M, Worku L, Tekeste Z. Cross-sectional study on the prevalence of intestinal parasites and associated risk factors in Teda Health Centre, northwest Ethiopia. ISRN parasitology. 2013;2013:757451.

51. Mara D, Lane J, Scott B, Trouba D. Sanitation and health. PLoS Med. 2010; 7(11):e1000363.

52. Lewin S, Norman R, Nannan N, Thomas E, Bradshaw D, Collaboration SACRA. Estimating the burden of disease attributable to unsafe water and lack of sanitation and hygiene in South Africa in 2000. S Afr Med J. 2007; 97(8):755-62.

53. Newell DG, Koopmans M, Verhoef L, Duizer E, Aidara-Kane A, Sprong H, Opsteegh M, Langelaar M, Threfall J, Scheutz F. Food-borne diseases-the challenges of 20years ago still persist while new ones continue to emerge. Int J Food Microbiol. 2010;139:S3-S15.

54. Kucik CJ, Martin GL, Sortor BV. Common intestinal parasites. Am Fam Physician. 2004;69(5):1161-8.

55. Feachem R, Mara DD, Bradley DJ. Sanitation and disease. Washington DC: Wiley; 1983.

56. Mulatu G, Zeynudin A, Zemene E, Debalke S, Beyene G. Intestinal parasitic infections among children under five years of age presenting with diarrhoeal diseases to two public health facilities in Hawassa, South Ethiopia. Infectious Dis Poverty. 2015;4(1):49.

\section{Ready to submit your research? Choose BMC and benefit from:}

- fast, convenient online submission

- thorough peer review by experienced researchers in your field

- rapid publication on acceptance

- support for research data, including large and complex data types

- gold Open Access which fosters wider collaboration and increased citations

- maximum visibility for your research: over $100 \mathrm{M}$ website views per year

At BMC, research is always in progress.

Learn more biomedcentral.com/submissions 